\title{
Correction to: IMMPACT-recommended outcome measures and tools of assessment in burning mouth syndrome RCTs: an international Delphi survey protocol
}

Barbara Carey ${ }^{1}$, Arwa M. Farag ${ }^{2,3}$, Cibele Nasri-Heir ${ }^{4}$, Gary D. Klasser ${ }^{5}$, Anura Ariyawardana ${ }^{6,7}$, Milda Chmieliauskaite ${ }^{8}$, Andrea Sardella ${ }^{9}$, Charles R. Carlson ${ }^{10}$, Craig S. Miller ${ }^{11}$, Lina Mejia ${ }^{12}$, Francis E. O'Neill ${ }^{13}$ and Ruy Albuquerque ${ }^{1,14^{*}}$

Correction to: Trials (2020) 21:711

https://doi.org/10.1186/s13063-020-04640-4

Following publication of the original article [1], the authors expressed their preference for their first names to be displayed in full, not just by initials.
Author details
'Oral Medicine Department, Guy's and St. Thomas Hospital NHS Foundation Trust, King's College London, London, UK. ${ }^{2}$ Department of Oral Diagnostic Sciences, Faculty of Dentistry, King AbdulAziz University, Jeddah, Saudi Arabia. ${ }^{3}$ Division of Oral Medicine, Department of Diagnostic Sciences, Tufts School of Dental Medicine, Boston, MA, USA. ${ }^{4}$ Department of Diagnostic Sciences, Center for Temporomandibular Disorders and Orofacial Pain, Rutgers School of Dental Medicine, The State University of New Jersey, Newark, NJ, USA. ${ }^{5}$ Department of Diagnostic Sciences, School of Dentistry, Louisiana State University Health Sciences Center, New Orleans, LA, USA. ${ }^{6}$ College of Medicine and Dentistry, James Cook University, Cairns, Queensland, Australia. ${ }^{7}$ Metro South Oral Health, Brisbane, Queensland, Australia. ${ }^{8}$ Department of Oral and Maxillofacial Medicine and Diagnostic Sciences, School of Dental Medicine, Case Western Reserve University, Cleveland, OH, USA. ${ }^{9}$ Department of Biomedical, Surgical and Dental Sciences, Unit of Oral Medicine, Oral Pathology and Gerodontology, University of Milan, Milan, Italy. ${ }^{10}$ Orofacial Pain Clinic, College of Dentistry, University of Kentucky, Lexington, KY, USA. ${ }^{11}$ Department of Oral Health Practice, College of Dentistry, University of Kentucky, Lexington, KY, USA. ${ }^{12}$ College of Dental Medicine, Nova Southeastern University, Fort Lauderdale, FL, USA. ${ }^{13}$ Department of Oral Surgery, School of Dentistry, University of

Liverpool, Liverpool, UK. ${ }^{14}$ Department of Oral Medicine, Faculty of Dentistry, Oral Craniofacial Sciences, King's College London, Floor 22, Guy's Tower, London SE1 9RT, UK.

Published online: 22 March 2021

\section{Reference}

1. Carey B, et al. IMMPACT-recommended outcome measures and tools of assessment in burning mouth syndrome RCTs: an international Delphi survey protocol. Trials. 2020;21:711. https://doi.org/10.1186/s13063-020-0464 $0-4$

The original article can be found online at https://doi.org/10.1186/s13063020-04640-4.

* Correspondence: rui.albuquerque@gstt.nhs.uk

'Oral Medicine Department, Guy's and St. Thomas Hospital NHS Foundation Trust, King's College London, London, UK

${ }^{14}$ Department of Oral Medicine, Faculty of Dentistry, Oral Craniofacial Sciences, King's College London, Floor 22, Guy's Tower, London SE1 9RT, UK Full list of author information is available at the end of the article

C The Author(s). 2021 Open Access This article is licensed under a Creative Commons Attribution 4.0 International License, which permits use, sharing, adaptation, distribution and reproduction in any medium or format, as long as you give appropriate credit to the original author(s) and the source, provide a link to the Creative Commons licence, and indicate if changes were made. The images or other third party material in this article are included in the article's Creative Commons licence, unless indicated otherwise in a credit line to the material. If material is not included in the article's Creative Commons licence and your intended use is not permitted by statutory regulation or exceeds the permitted use, you will need to obtain permission directly from the copyright holder. To view a copy of this licence, visit http://creativecommons.org/licenses/by/4.0/. The Creative Commons Public Domain Dedication waiver (http://creativecommons.org/publicdomain/zero/1.0/) applies to the data made available in this article, unless otherwise stated in a credit line to the data. 